\title{
Late relapse of IgM nephropathy-associated nephrotic syndrome after repeated administration of immune checkpoint inhibitor against pulmonary adenocarcinoma
}

\author{
Kentaro Odani ${ }^{1}$, Mitsuhiro Tachibana $^{1}$, Fumiaki Nogaki ${ }^{1}$, and Yutaka Tsutsumi ${ }^{2}$ \\ ${ }^{1}$ Shimada Municipal Hospital \\ ${ }^{2}$ Pathos Tsutsumi
}

November 5, 2020

\begin{abstract}
A man aged 60's suffered nephrotic syndrome with IgM nephropathy seven years earlier. Four years later, immune-checkpoint inhibitors (ICPIs) were administered against metastasizing pulmonary adenocarcinoma. Sixty-two weeks after 21 ICPIs injections, the cancer vanished but nephrotic syndrome relapsed. Acute pancreatitis followed and usual interstitial pneumonia exacerbated, as late-onset immune-related adverse-events.
\end{abstract}

\section{Hosted file}

ICPIs and IgMN(CCR).pdf available at https://authorea.com/users/373231/articles/490990-laterelapse-of-igm-nephropathy-associated-nephrotic-syndrome-after-repeated-administrationof-immune-checkpoint-inhibitor-against-pulmonary-adenocarcinoma

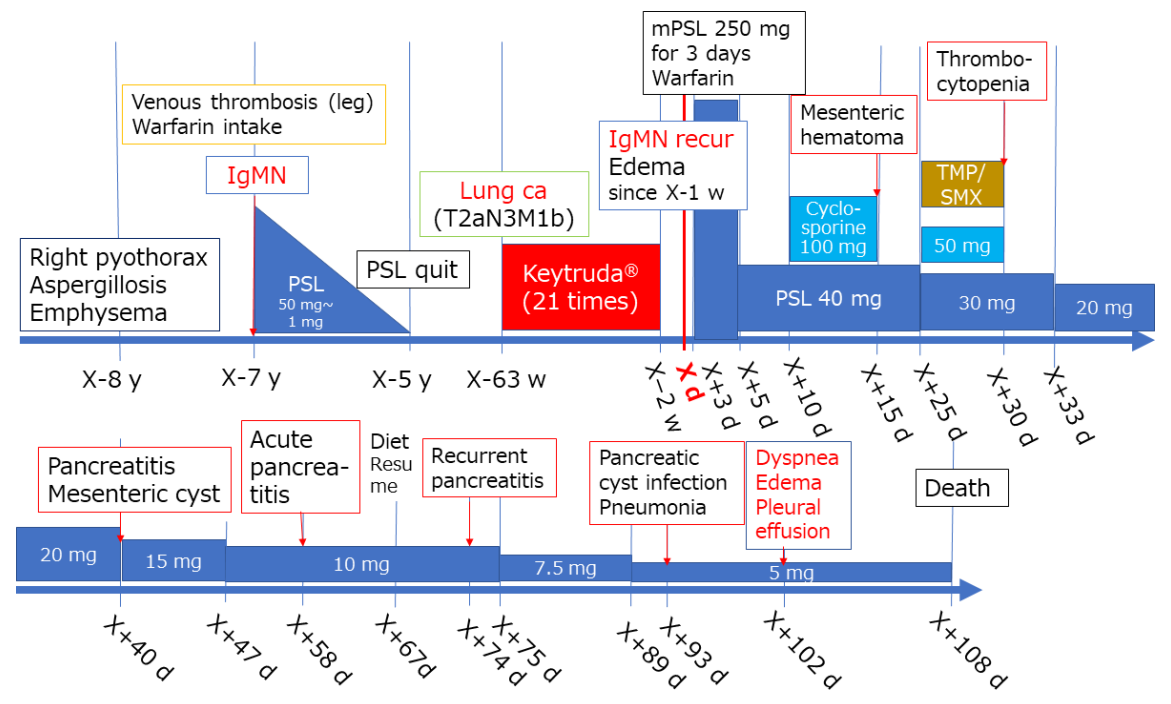



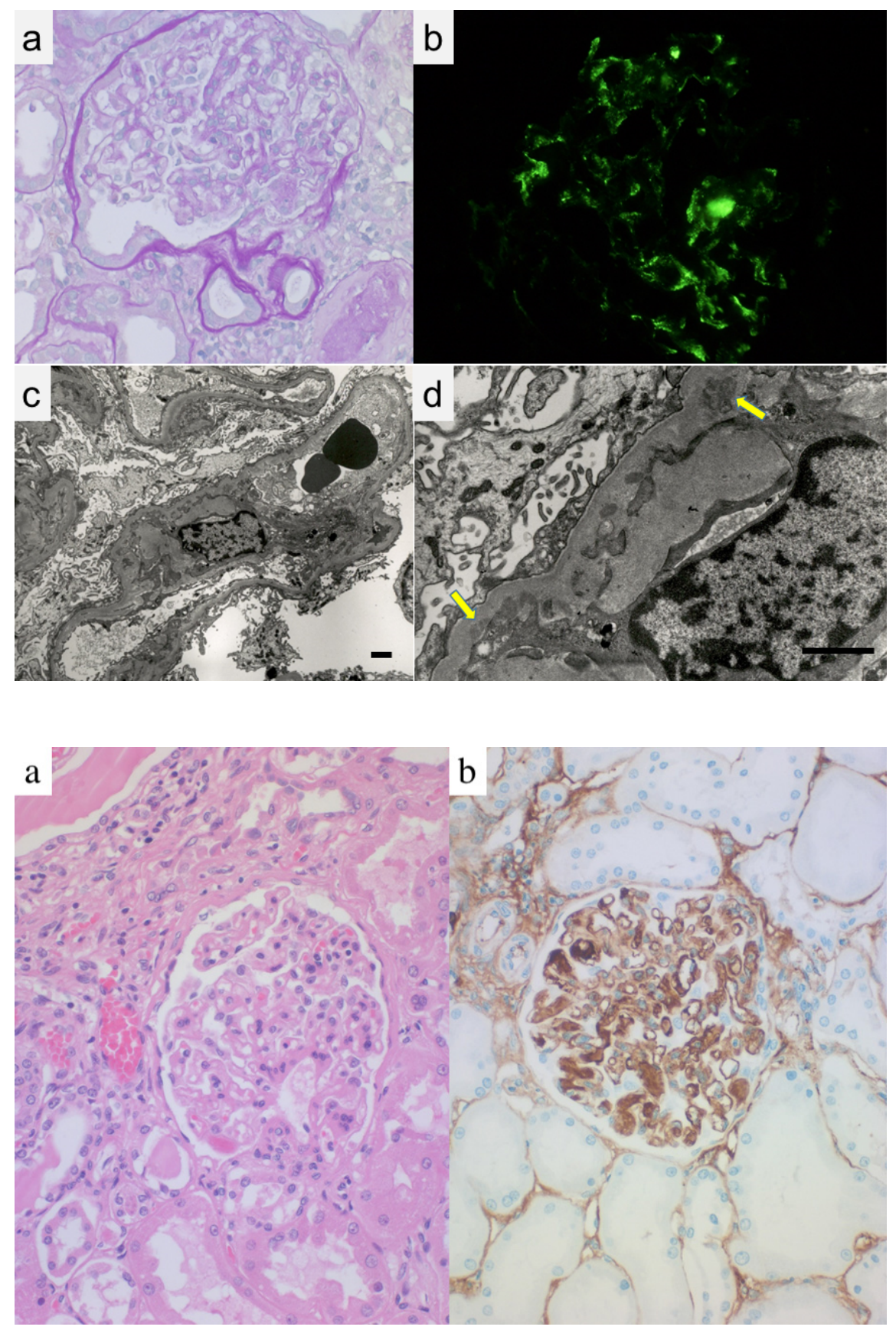

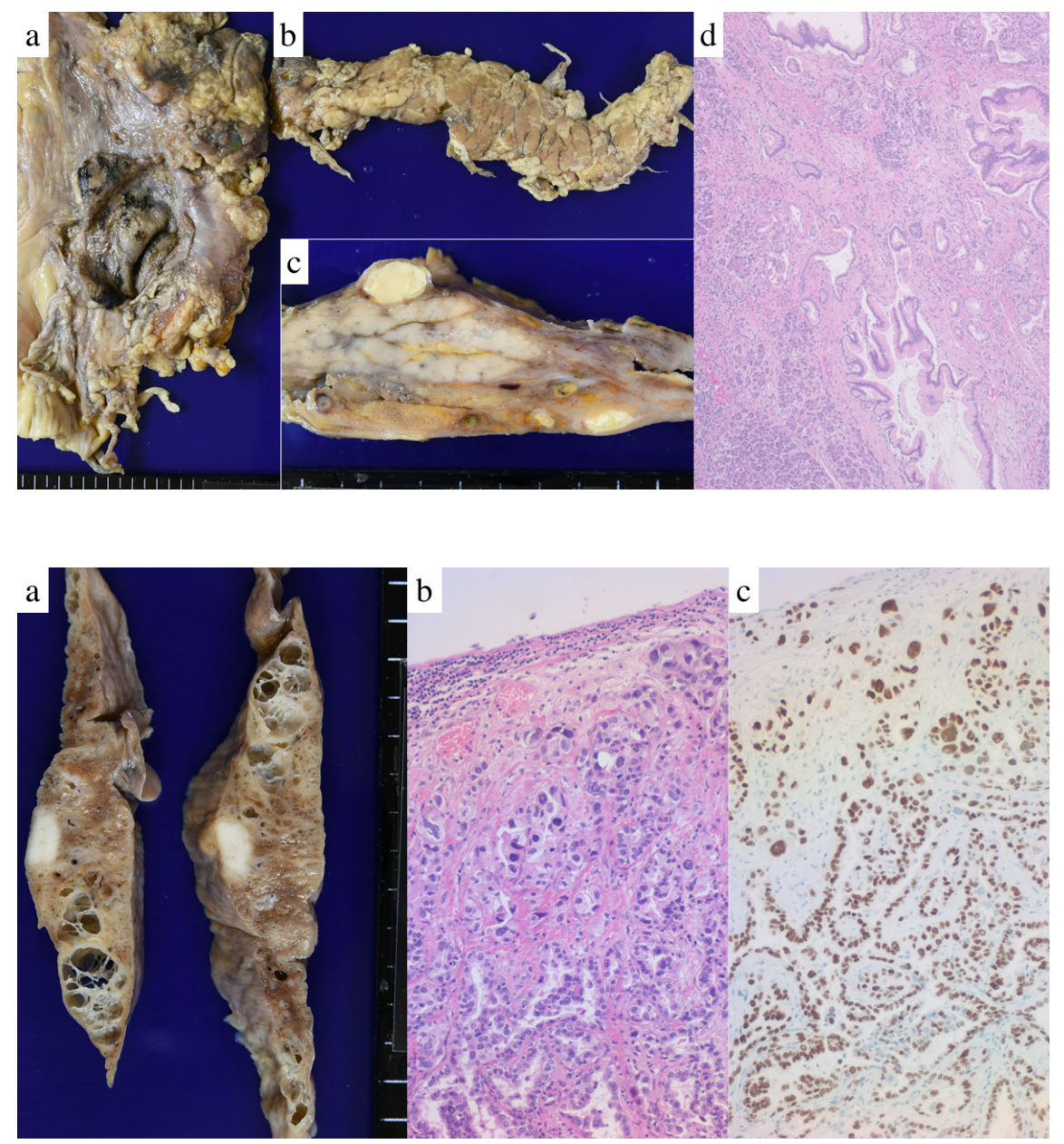

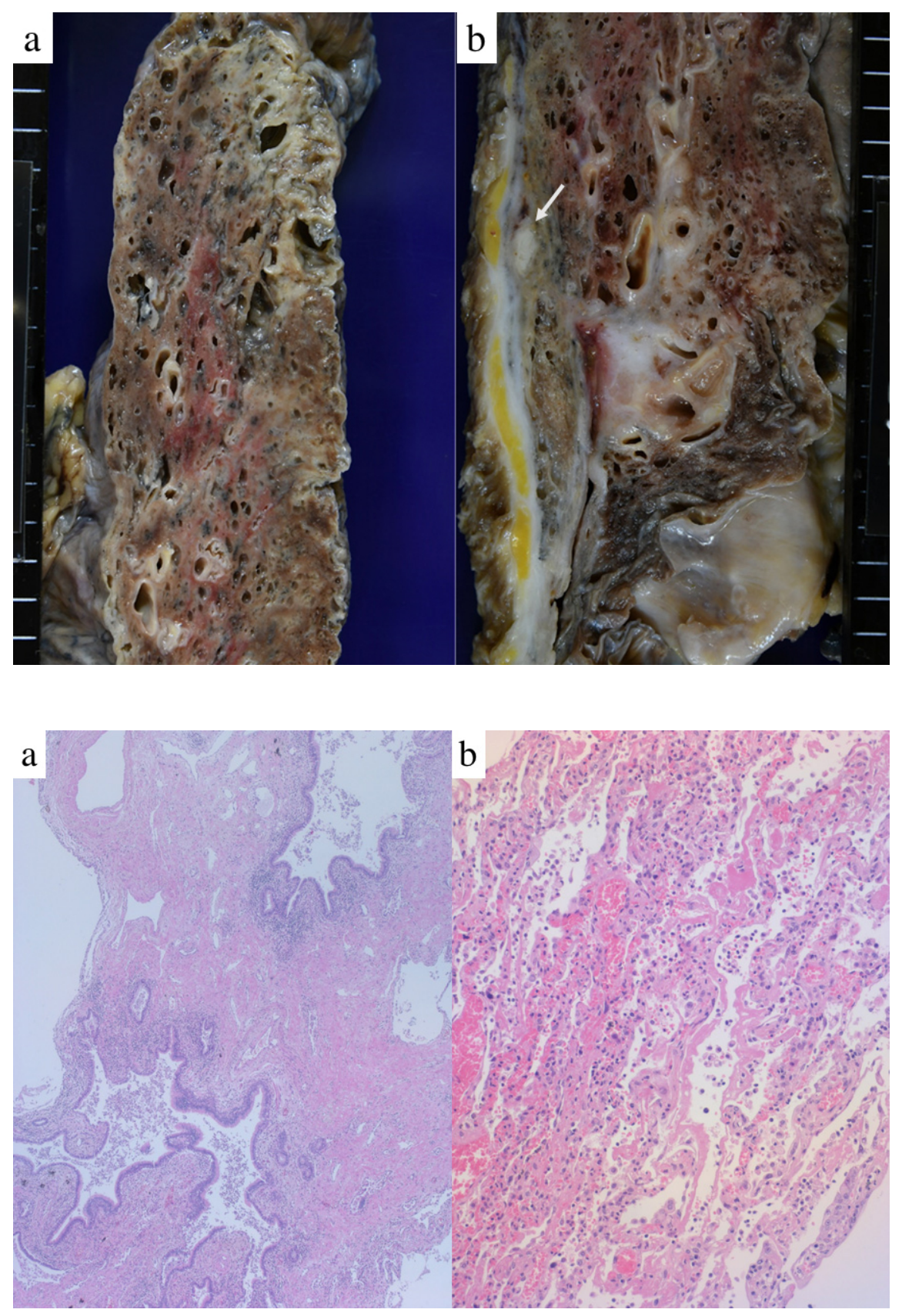